\title{
O governo eletrônico no Brasil: perspectiva histórica a partir de um modelo estruturado de análise*
}

\author{
Eduardo Henrique Diniz** \\ Alexandre Fernandes Barbosa*** \\ Alvaro Ribeiro Botelho Junqueira**** \\ Otavio Prado*****
}

\begin{abstract}
* Artigo recebido em jan. 2007 e aceito em jul. 2008.
** Doutor e mestre em administração de empresas pela Escola de Administração de Empresas de São Paulo da Fundação Getulio Vargas (Eaesp/FGV). Professor da Fundação Getulio Vargas (Eaesp). Endereço: Av. Nove de Julho, 2029 - CEP 01313-902, São Paulo, SP, Brasil. E-mail: ediniz@fgvsp.br.

**** Mestre em administração pela University of Bradford, UK, mestre em ciência da computação pela UFMG, pós-graduado em marketing pela Escola de Pós-Graduação em Economia da Fundação Getulio Vargas (EPGE /FGV), pós-graduado em finanças empresariais pela EPGE/FGV, doutorando em administração de empresas pela Eaesp/FGV. Endereço: Rua Apinagés, 352, ap. 141-A — CEP 05017-000, São Paulo, SP, Brasil. E-mail: abarbosa@gvmail.br.

**** Mestrando em administração de empresas pela Eaesp/FGV. Endereço: Avenida Nove de Julho, 2029 _ CEP 01313-902, São Paulo, SP, Brasil. E-mail: arbjunqueira@yahoo.com.br.

$* * * * *$ Doutorando em administração de empresas pela Eaesp/FGV, mestre em administração de empresas pela Eaesp/FGV. Endereço: Avenida Nove de Julho, 2029 — CEP 01313-902, São Paulo, SP, Brasil. E-mail: otavioprado@fgvsp.br.
\end{abstract}


KEY WORDS: electronic government; public policies; information technology and communications; assessment of government programs; e-gov analysis model.

O desenvolvimento do Programa de Governo Eletrônico brasileiro foi iniciado em 2000, durante a gestão do presidente Fernando Henrique Cardoso, e atravessa hoje a terceira gestão de dois diferentes governos. Embora a perspectiva tecnológica tenha alta relevância na análise histórica desse programa, este artigo propõe uma abordagem metodológica para a análise do Programa de Governo Eletrônico apoiada em um modelo de referência que incorpora as suas diversas etapas de desenvolvimento, seus atores, suas relações e fatores intervenientes. A validação do modelo foi feita por meio de levantamento empírico, em que foram utilizadas entrevistas semiestruturadas com atores-chave do processo.

Electronic government in Brazil: a historical perspective from a structured model of analysis

The development of the Brazilian Electronic Government Program started in 2000, during the Ferrnando Henrique Cardoso administration. Today it is in its third management of two different administrations. Although the technological perspective has high relevance in the historical analysis of this program, this article suggests a methodological approach for the analysis of the Electronic Government Program supported by a reference model that incorporates its different stages of development, its actors, its intervening relations and factors. The model was validated by means of an empirical survey with semi-structured interviews with key actors of the process.

\section{Introdução}

A ideia de governo eletrônico, embora associada ao uso de tecnologia de informação no setor público, ultrapassa essa dimensão. Em alguns casos, está vinculada à modernização da administração pública por meio do uso de tecnologias de informação e comunicação (TICs) e na melhoria da eficiência dos processos operacionais e administrativos dos governos (Agune e Carlos, 2005; Osborne, 1997). Em outros casos, está claramente associada ao uso de internet no setor público para prestação de serviços públicos eletrônicos (Ronaghan, 2002; Medeiros, 2004; Grant e Chau, 2005).

Entre as causas determinantes da adoção das TICs de forma estratégica e intensiva pelos governos em seus processos internos e na melhoria dos serviços públicos prestados à sociedade destacam-se: o uso intensivo das TICs pelos cidadãos, empresas privadas e organizações não governamentais; a migração da informação baseada em papel para mídias eletrônicas e serviços online e o avanço e universalização da infraestrutura pública de telecomunicações e 
da internet. Outras causas estão associadas às forças provenientes do próprio movimento de reforma do Estado, da modernização da gestão pública e da necessidade de maior eficiência do governo. Consequentemente, temas como desempenho, eficiência, eficácia, transparência, mecanismos de controle, qualidade do gasto público e prestação de contas, relacionados ao processo de modernização da gestão pública, foram associados ao processo de construção de programas de governo eletrônico. O desdobramento desses temas em políticas públicas e iniciativas concretas, explicitadas nos programas de governo, requerem o uso de tecnologia, tornando os programas de governo eletrônico elementos alavancadores de novos patamares de eficiência da administração pública.

Dentro de uma perspectiva histórica e temporal, pode-se afirmar que a expressão governo eletrônico, ou e-gov, ${ }^{1}$ começou a ser utilizada com mais frequência após a disseminação e consolidação da ideia de comércio eletrônico (e-commerce), na segunda metade da década passada (Diniz, 2000; Lenk e Traunmüller, 2002) e, a partir daí, ficou completamente associada ao uso que se faz das TICs nos diversos níveis de governo. Em artigos recentes, autores têm trabalhado no entendimento das fases da evolução do uso de TIC no setor público no Brasil. Focando na estrutura do processo de informatização, Reinhard e Dias (2005) classificaram quatro grandes períodos do uso de TIC no setor público: pioneirismo (dos anos 1950 até meados dos anos 1960); centralização (de meados dos 1960 até o final dos 1970); terceirização (anos 1980) e governo eletrônico propriamente dito (a partir dos anos 1990). Diniz (2005) faz sua análise a partir dos trabalhos apresentados no Congresso de Informática Pública (Conip), o principal fórum brasileiro de debates sobre as práticas inovadoras no setor público sustentadas pelas TICs. Essa avaliação, com foco nas aplicações desenvolvidas, divide-se em três fases: gestão interna (1970 a 1992); serviço e informações ao cidadão (1993 a 1998) e a entrega de serviços via internet (a partir de 1999).

Embora a visualização da evolução do uso das TICs em fases contribua para o entendimento do processo no Brasil, quando se analisa a ampla utilização dos recursos da internet e o desenvolvimento da sociedade da informação, há a necessidade de proposição de um modelo de avaliação dos rumos do governo eletrônico no contexto brasileiro mais consistente.

\footnotetext{
${ }^{1}$ Embora governo eletrônico seja um dos termos mais encontrados na literatura, existem outros termos com o mesmo significado, como por exemplo: e-gov, electronic government, e-government, e-governo, wired-government, governo digital, governo virtual, Estado virtual, governança eletrônica. 
É exatamente nesse ponto que este artigo está focado. A partir da análise histórica da implantação do governo eletrônico pelo governo federal brasileiro, dos fatores políticos, institucionais e técnicos críticos na concepção, construção, implementação e avaliação de projetos de governo eletrônico e também dos atores envolvidos na construção desses projetos, propõe-se um modelo de referência que identifique o conjunto de relações mais frequentemente observadas em seu processo de implementação. Na primeira parte do artigo será apresentado um panorama do tema governo eletrônico, particularmente no contexto brasileiro. Em seguida, um detalhamento da metodologia, apresentando o modelo de referência e seu embasamento teórico. $\mathrm{Na}$ terceira parte, é feita a análise dos dados coletados em campo junto aos atores-chave por meio de entrevistas semiestruturadas, que procurou testar a adequação do modelo de referência. Por fim, são feitas considerações finais e apresentadas as conclusões.

\section{0 governo eletrônico no setor público brasileiro}

As iniciativas de reforma e modernização do setor público e do Estado se intensificaram não apenas como consequência da crise fiscal dos anos 1980, mas também como resultado do esgotamento do modelo de gestão burocrática e do modo de intervenção estatal. O movimento conhecido por reforma da gestão pública (Bresser-Pereira, 2002) ou new public management (Ferlie et al., 1996) teve como cerne a busca da excelência e a orientação dos serviços ao cidadão. Esse movimento baseou-se em princípios gerenciais voltados a resultados, eficiência, governança e orientação da gestão pública para práticas de mercado. Behn (1998) define a nova gestão pública como um conjunto de conceitos novos, aplicados à administração pública, consistindo em vários componentes inter-relacionados, e o uso da tecnologia como um dos fatores necessários para alcançar resultados de alto desempenho.

De forma análoga ao que ocorre no setor privado, o ambiente no qual se desenvolvem as práticas de gestão pública sofre influências das tendências e fenômenos sociais, políticos, econômicos e tecnológicos (Pollit e Bouckaert, 2000). Assim, modelos de gestão são aplicados no setor privado. Apesar disso, essa adequação de modelos de gestão não é trivial e deve levar em consideração as características inerentes ao setor público, diferentes das do setor privado (Bretschneider, 1990; Torres, 1997). Com isso, um dos focos de ação dos governos contemporâneos tem sido a elaboração de políticas públicas eficazes que supram as necessidades individuais, institucionais e 
regionais da sociedade, promovendo o desenvolvimento social e econômico (Barbosa Filho, 2000). Concomitantemente, os governos enfrentam também o desafio de dar suporte ao desenvolvimento de políticas públicas voltadas a tecnologias que promovam um salto qualitativo, exigido na prestação dos serviços públicos que atendam as demandas da sociedade contemporânea (Barbosa et al., 2005). Esse desafio é fruto da diferença entre os níveis de adoção de tecnologia encontrados no setor privado e no setor público, já que os elevados índices de adoção de tecnologia e de automação de processos operacionais, produtivos e administrativos no setor privado criaram um novo paradigma de eficiência que o setor público precisa alcançar.

O uso estratégico das TICs como elemento viabilizador de um novo modelo de gestão pública evoluiu para o que é hoje chamado de governo eletrônico. Segundo Agune e Carlos (2005), governo eletrônico pode ser entendido como um conjunto de ações modernizadoras vinculadas à administração pública, que começam a ganhar visibilidade no final da década de 1990. Além de ser uma das principais formas de modernização do Estado, o governo eletrônico está fortemente apoiado numa nova visão do uso das tecnologias para a prestação de serviços públicos, mudando a maneira pela qual o governo interage com o cidadão, empresas e outros governos. Governo eletrônico não se restringe à simples automação dos processos e disponibilização de serviços públicos por meio de serviços online na internet (Abranson e Means, 2001), mas na mudança da maneira como o governo, pelo uso da TIC, atinge os seus objetivos para cumprimento do papel do Estado. Isso inclui a melhoria dos processos da administração pública, aumento da eficiência, melhor governança, elaboração e monitoramento das políticas públicas, integração entre governos, e democracia eletrônica, representada pelo aumento da transparência, da participação democrática e accountability dos governos ${ }^{2}$ (Prado, 2004). Além desses temas, o combate à exclusão digital é abordado como importante dimensão dos programas de e-governo (Chain et al., 2004; Ferrer e Santos, 2004).

\footnotetext{
${ }^{2}$ Podemos entender accountability democrática como um princípio que se expressa em mecanismos institucionais que devem constranger os governos continuamente a prestar contas à sociedade e a outros atores no sistema político (Legislativo, Judiciário etc.). Para a sua plena realização, tais mecanismos institucionais devem garantir o controle público das ações dos governantes, permitindo aos cidadãos não só serem informados sobre aquelas ações, mas também possibilitando a eles influir na definição das metas coletivas, não somente através das eleições, mas ao longo dos mandatos dos seus representantes, garantindo a responsabilização ininterrupta dos governos.
} 


\section{Modelo de referência para análise da história do e-gov no Brasil}

O modelo de referência proposto neste artigo pretende servir de suporte metodológico ao estudo e análise histórica de programas de governo eletrônico. Ele apresenta uma visão das principais etapas do processo, os atores envolvidos, seus interesses e competências e os aspectos influenciadores que impactam o resultado final do programa. Adicionalmente, o modelo considera que o relacionamento entre os atores e as etapas do processo reflete o grau de intervenção deles em seus diversos momentos de construção. O modelo parte do pressuposto de que o conjunto de relacionamentos decorrentes das interações entre atores e fatores influenciadores ao longo das diferentes etapas cria relações de diferentes intensidades e naturezas, que impactam o desenvolvimento, consolidação e institucionalização de um programa de governo eletrônico. A figura 1 explicita as possíveis relações entre atores e fatores influenciadores nas cinco fases consideradas do processo: elaboração de políticas públicas, concepção de projetos, implantação de projetos, operação e manutenção e avaliação e controle.

Figura 1

Modelo de referência para estudo e análise de e-gov

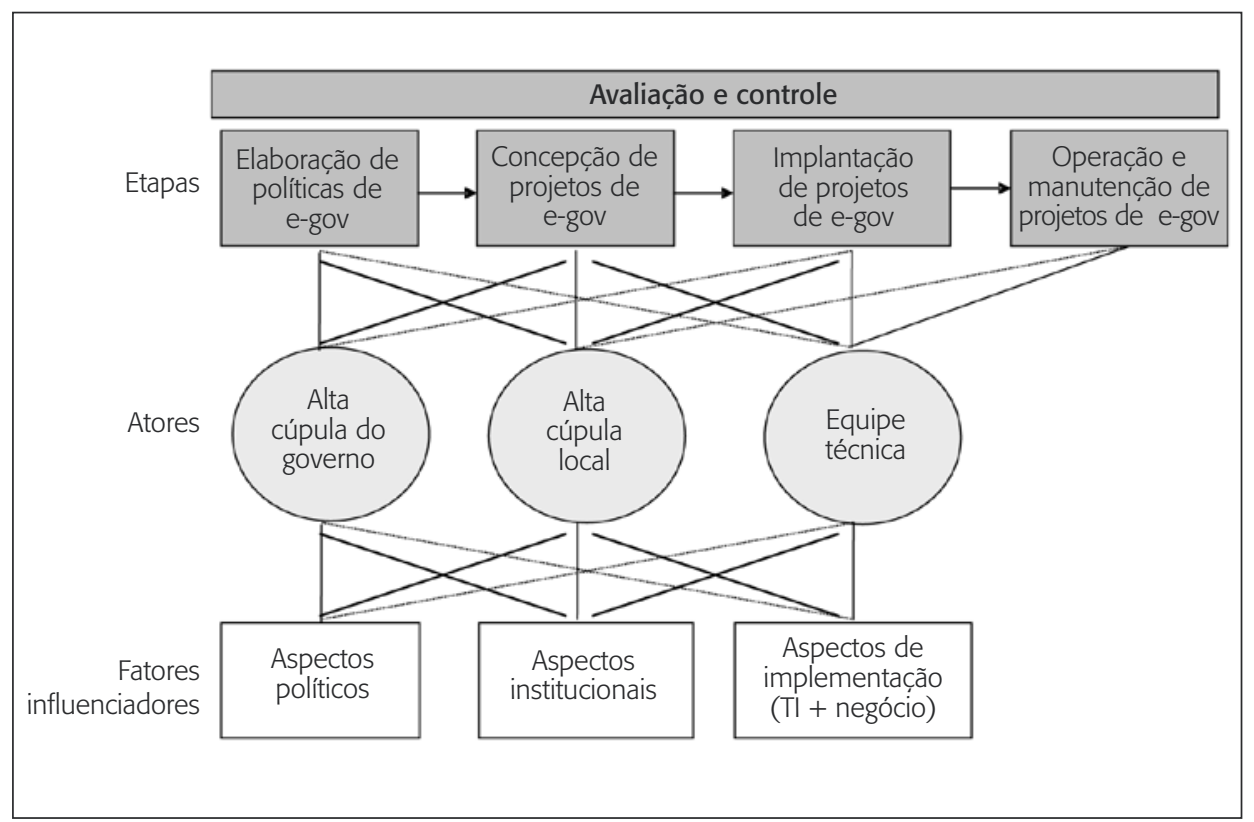




\section{Etapas do processo}

A implementação efetiva de um programa de governo eletrônico deve ser entendida como um processo composto de várias etapas que incorporam aspectos políticos, técnicos e organizacionais, desde a fase de concepção até a implantação e avaliação. Essas etapas, apesar de específicas para programas de e-gov, seguem, em linhas gerais, as etapas descritas do ciclo das políticas públicas (policy cycle), tal como Frey (2000) e Peters (1996) apontam. Esses autores estabeleceram uma série de passos para a formulação, implementação e avaliação de políticas públicas, variando ligeiramente no número de etapas e no enfoque dado a cada uma. Essas etapas não ocorrem necessariamente de forma linear, e têm como objetivo fornecer quadros de referência que auxiliem a análise. As etapas do processo de implementação de políticas públicas voltadas para governo eletrônico, baseadas no modelo de referência proposto neste artigo, foram divididas conforme está no quadro 1.

$$
\text { Quadro } 1
$$

Etapas do processo de programas de e-gov e de políticas públicas

\begin{tabular}{|c|c|c|}
\hline $\begin{array}{l}\text { Etapas propostas por } \\
\text { Peters (1996) - ciclo de } \\
\text { políticas públicas }\end{array}$ & $\begin{array}{l}\text { Etapas propostas por Frey }(2000) \\
\text { - ciclo de políticas públicas }\end{array}$ & $\begin{array}{l}\text { Etapas propostas pelos autores } \\
\text { para programas de e-governo }\end{array}$ \\
\hline $\begin{array}{l}\text { Definição do problema } \\
\text { v Agenda setting }\end{array}$ & $\begin{array}{l}\text { Vercepção e definição de problemas } \\
\text { v Agenda setting }\end{array}$ & $\begin{array}{l}\text { Vlaboração de políticas públicas } \\
\text { de e-gov }\end{array}$ \\
\hline $\begin{array}{l}\text { Formulação } \\
\text { vegitimação } \\
\text { v Conexão a recursos }\end{array}$ & V Elaboração de programas e decisão & - Concepção de projetos de e-gov \\
\hline v Implementação & v Implementação de políticas & - Implantação de projetos de e-gov \\
\hline \multirow[t]{2}{*}{ v Avaliação } & V Avaliação de políticas e correção & V Avaliação e controle \\
\hline & & $\begin{array}{l}\text { V Operação e manutenção de } \\
\text { programas de e-gov }\end{array}$ \\
\hline
\end{tabular}

A etapa de elaboração de políticas públicas de e-gov consiste na elaboração das principais diretrizes e direcionamentos de governo eletrônico que subsidiarão as políticas públicas. Essas políticas públicas são preferencialmente comunicadas aos ambientes interno e externo por meio de instrumentos formais de comunicação, disponíveis na administração pública. Um exemplo dessa fase é a "Proposta de política de governo eletrônico para o Poder Executivo Federal" (Brasil, 2000). Entre as etapas que compõem o modelo teórico proposto, essa possui destacada importância, e é representada pelo conjunto de atividades 
realizadas por atores políticos da alta cúpula dos governos, cujo objetivo é alinhar os interesses entre as áreas-meio e as áreas-fim da administração pública. Para que tais políticas sejam bem-sucedidas, Checchi e colaboradores (2003) propõem que seja enfocada a capacidade de construção e retenção do conhecimento dentro do próprio país, em contrapartida ao simples consumo de fontes externas. Tendem a ser mais efetivas políticas de TIC mais flexíveis, capazes de acomodar mudanças ambientais e tecnológicas, assim como políticas integradas com outros setores, tais como educação e infraestrutura, como mostram os exemplos de países como Irlanda, Singapura, Coréia, Costa Rica e Taiwan (Checchi et al., 2003).

A etapa de concepção de projetos de e-gov envolve a criação de novos projetos de e-gov ou a convergência dos projetos existentes com as políticas anteriormente concebidas. Nessa etapa são definidos o macroescopo do projeto, sua fonte orçamentária e suas principais inter-relações e dependências com outros projetos e/ou recursos. Essa etapa em geral é o resultado da identificação das atividades e ações necessárias para alcançar os objetivos esperados, e deve indicar os meios utilizados para atingi-los, os recursos necessários, como serão obtidos e as formas de avaliação dos resultados. Já que o processo de concepção de projetos não é trivial, normalmente é necessário ter um conhecimento mínimo do contexto do negócio. Por exemplo, no caso do estado de São Paulo, existem comitês setoriais responsáveis por propor e analisar esse tipo de ação (Agune e Carlos, 2005).

A etapa de implantação de projetos de e-gov envolve a efetiva execução dos projetos definidos anteriormente. Envolve um maior detalhamento técnico do projeto, o que pode levar a uma redefinição do escopo do projeto ou sua segmentação em subprojetos. Nessa etapa são normalmente definidos os mecanismos de gestão que serão utilizados, de forma a alcançar um maior controle da execução e dos recursos envolvidos, visando maior eficiência e desempenho dos projetos a serem implementados. Autores como Gil-Garcia e Pardo (2005), ao classificarem os principais desafios e fatores críticos de sucesso na implementação de um projeto de governo eletrônico, indicam que as principais preocupações estão no limite entre a transparência e o sigilo dos dados dos cidadãos, nas questões relacionadas à integração e compatibilidade tecnológica e nos problemas de continuidade orçamentária e rigidez burocrática, indicando que o sucesso depende fortemente do adequado tratamento dos aspectos tecnológicos, organizacionais, legais e políticos.

A etapa de avaliação e controle engloba a definição dos mecanismos de avaliação e controle que serão utilizados para a gestão efetiva dos programas de e-gov. Tais mecanismos visam avaliar os níveis específicos de desempenho 
e confiabilidade, considerando o escopo, custos e prazos definidos em cada projeto. Como os projetos podem gerar resultados de natureza tangível e intangível, devem ser criados indicadores de desempenho que possam tornar quantificáveis e mensuráveis todos os seus resultados.

A etapa de operação e manutenção de projetos de e-gov se refere às manutenções evolutivas e corretivas do programa, assim como à sua operação cotidiana. As atividades mais convencionais envolvem a atualização de informações, continuidade na prestação de serviço, ajustes e refinamentos de processos ou sistemas, entre outras. Gil-Garcia e Pardo (2005) apontam que questões como restrições orçamentárias e descontinuidade de gestão podem impactar os programas de TIC do setor público. Além disso, é razoável considerar que problemas relacionados à manutenção da equipe técnica, com expertise no sistema, associados à eventual deficiência documental dos sistemas de informação, podem resultar em pontos de risco para a continuidade dos programas de e-gov. O conjunto de indicadores de desempenho necessário deve permitir a medição, avaliação e controle do desempenho dos programas de egov, possibilitando sua avaliação gerencial e operacional. Gupta e Jana (2003) sugerem um modelo que envolve indicadores quantitativos (hard measures), indicadores qualitativos (soft measures) e rankings. O critério de escolha do tipo de medição deve ser coerente com o grau de detalhamento das informações existentes e, em geral, são complementares. Como exemplo, avaliar um projeto unicamente pela sua vertente financeira (hard measure) possivelmente não refletirá se a expectativa do usuário foi atendida (soft measure).

\section{Atores envolvidos}

Os principais atores, políticos e técnicos, responsáveis pela execução de cada uma das etapas descritas no modelo teórico apresentado, são elementos centrais no processo de construção e legitimação de projetos de e-gov. Na proposição do modelo, a influência sobre a execução de cada etapa é dada principalmente pelas características desses atores, que são influenciados por aspectos externos e por suas preferências. As interações dos atores ocorrem no âmbito da arena das políticas (policy arena), variando entre consenso e conflito conforme o impacto da política em questão. Frey (2000) descreve quatro tipos de políticas: as distributivas (geração de benefícios sem custos), as redistributivas (deslocamento de recursos), as regulatórias (ordens e proibições) e as constitutivas (estruturantes), indicando que as políticas de caráter distributivo têm menor chance de gerar conflito, já que têm caráter consensual, ao contrário 
das políticas redistributivas, orientadas ao conflito. Pollit e Bouckaert (2000), ao incorporarem a visão dos atores em seu modelo de reforma da gestão pública apontam que as "elites", ao serem influenciadas, respondem com um pacote de políticas de implementação viável. Particularmente no caso das TIs, a participação dos gestores apresenta-se como fator fundamental para a sua efetividade, em alguns casos é considerada a mais relevante (Aladwani, 2001).

É importante ressaltar que os atores não são apenas os gestores públicos, já que outros representantes da sociedade normalmente estão presentes no processo. Para Checchi e colaboradores (2003), devem ser consideradas também as organizações privadas, as instituições acadêmicas, os sindicatos, as instituições religiosas e as organizações não governamentais, além do próprio governo, como integrantes importantes na concepção de políticas de TIC governamentais.

O modelo proposto considera três níveis principais de atores, sugerindo uma interação colaborativa e sinérgica nas etapas de implementação de um programa de e-gov:

v alta cúpula de governo - a alta cúpula do nível estratégico do governo, representada pelos entes responsáveis pela concepção das diretrizes e políticas públicas do governo, é formada por atores de alta representatividade e alta projeção na esfera em que atuam e com poder político elevado. Embora sejam em sua maioria atores da área governamental, também é comum encontrar representantes de organizações privadas e da sociedade civil;

v alta cúpula local - a alta cúpula local é composta de dirigentes de instituições ou de nível executivo ligadas às áreas-fim e áreas-meio da administração pública. São geralmente bastante envolvidos no processo de concepção e acompanhamento dos projetos de governo eletrônico e representam o nível intermediário, responsável pelo encaminhamento das pendências dos grupos técnicos implementadores;

v equipe técnica - representam a equipe que detém os conhecimentos técnicos para detalhamento e implementação do projeto, tanto da área de TIC quanto da de negócios. As empresas de processamento de dados governamentais, assim como técnicos de órgãos públicos e especialistas da sociedade civil, geralmente compõem esse grupo.

\section{Fatores influenciadores}

Não há dúvida que existem aspectos externos que influenciam os atores na consecução dos objetivos de uma determinada atividade, destacando-se entre eles 
as influências políticas e socioeconômicas, atuantes no processo de elaboração de políticas públicas. No planejamento de TIC em países em desenvolvimento, Aladwani (2001) sugere a existência de três fatores principais, que devem ser considerados quando do planejamento de TIC em organizações privadas: fatores de TI, fatores organizacionais e fatores ambientais. Além desses, fatores como a penetração de TI, o envolvimento e capacidade dos gestores, a adequabilidade de recursos e demais políticas governamentais também devem ser considerados. Assim, o modelo proposto considera três aspectos principais:

v aspectos políticos - demandas implícitas ou explícitas de atores que possuem interesses (stakeholders), envolvidos direta ou indiretamente no projeto. Segundo Tan e Pan Shan (2005), os stakeholders não podem ficar alheios às iniciativas de governo eletrônico e as organizações públicas devem ser proativas na identificação e envolvimento desses. Apesar disso, os autores sugerem que o governo não deve ceder a quaisquer demandas, mas adequálas aos seus projetos de forma colaborativa;

- aspectos institucionais - arranjos institucionais que influenciam as políticas ou projetos de e-gov, tais como a estrutura hierárquica funcional (organograma), a responsabilidade e poder dos atores envolvidos, o processo de contratação de serviços, o modelo de terceirização de TIC, o grau burocrático organizacional etc. Segundo Gil-Garcia e Pardo (2005), esses aspectos influenciam diretamente o grau de sucesso na implementação de projetos de e-gov;

- aspectos técnicos - influências técnicas no projeto, sejam elas referentes a TIC ou a questões de negócio, tais como os padrões tecnológicos utilizados, a complexidade técnica do projeto, a metodologia de desenvolvimento etc. Esses fatores estão fortemente relacionados com a etapa de implementação e implantação do projeto.

\section{Relações entre atores}

Ao analisar o papel das relações entre etapas, atores e fatores influenciadores, nota-se que os atores atuam mais intensamente nas etapas em que seu desempenho se mostra mais significativo. Parte dessas relações ocorre no que Frey (2000) chama de redes políticas (policy networks), definidas como "as interações das diferentes instituições e grupos tanto do Executivo, do Legislativo, como da sociedade na gênese e na implementação de políticas públicas" (Hedo, 1978, citado por Frey, 2000:221). O quadro 2 apresenta os pressu- 
postos relativos à intensidade da relação dos atores nas diferentes etapas de construção de um programa de governo eletrônico.

Quadro 2

Intensidade da relação dos atores nas diferentes etapas

\begin{tabular}{|lccccc|}
\hline & \multicolumn{5}{c|}{ Etapas do processo } \\
\cline { 2 - 6 } Atores & $\begin{array}{l}\text { Elaboração } \\
\text { de políticas }\end{array}$ & $\begin{array}{c}\text { Concepção } \\
\text { de projetos }\end{array}$ & $\begin{array}{c}\text { Implantação } \\
\text { de projetos }\end{array}$ & $\begin{array}{c}\text { Operação e } \\
\text { manutenção de } \\
\text { projetos }\end{array}$ & $\begin{array}{c}\text { Avaliação e } \\
\text { controle }\end{array}$ \\
\hline $\begin{array}{l}\text { Alta cúpula de } \\
\text { governo }\end{array}$ & Forte & Média & Fraca & Fraca & Forte \\
$\begin{array}{l}\text { Alta cúpula local } \\
\text { Equipe técnica }\end{array}$ & Média & Forte & Média & Fraca & Forte \\
\hline
\end{tabular}

\section{Metodologia de validação do modelo}

Com o objetivo de validar o modelo de referência proposto para a análise histórica do governo eletrônico no Brasil, foram utilizadas técnicas de pesquisa qualitativa, baseada na análise documental eletrônica do programa de governo federal e em entrevistas semiestruturadas com atores-chave no processo. Essa abordagem metodológica está alinhada ao objetivo do artigo, que é apresentar uma perspectiva histórica do governo eletrônico no Brasil. As entrevistas buscaram identificar os fatores influenciadores no programa, a saber: estrutura de coordenação, legislação e normas, financiamento do programa, agenda de projetos (tanto setoriais quanto transversais ao conjunto da administração pública) e aspectos da implementação do programa (liderança, coordenação e comunicação interburocrática e articulação com a sociedade).

Os documentos pesquisados foram os relatórios, portarias, leis, decretos e demais documentos relacionados às iniciativas, propostas e implementação do programa de governo eletrônico. As entrevistas foram realizadas com técnicos e políticos diretamente envolvidos no processo. Considerou-se para isso que a análise documental permite avaliar o nível de institucionalização do programa (Medeiros, 2004), enquanto a avaliação dos projetos (propostos e/ou implementados) pode indicar a direção em que o programa evoluiu. Já as entrevistas permitem capturar as motivações e peculiaridades do processo, muitas vezes não explicitadas pela análise documental e de projetos. 


\section{Análise de dados documentais}

Para a análise documental, os dados disponíveis sobre a documentação de projetos, leis, decretos e notícias foram coletados diretamente nos sites dos órgãos e entidades da administração pública federal. Para complementar, foram pesquisados artigos e publicações acadêmicas sobre o tema.

A história do governo eletrônico no Brasil está diretamente ligada ao desenvolvimento dos serviços de informática pública, oferecidos pelas empresas estaduais e municipais de processamento de dados, iniciado nos primeiros anos da década de 1960. Como na área privada, o uso de TIC foi encabeçado pelo setor financeiro, sendo as empresas de prestação de serviços de informática pública criadas inicialmente para processamento de dados e informações de natureza fiscal, em geral para a gestão de receitas e controle das despesas do governo. Agune e Carlos (2005) mostram que, a partir dessa demanda, a informática na gestão pública evoluiu ao longo do tempo para a entrega de serviços ao cidadão em vários canais de acesso. Embora essas empresas tenham se empenhado em acompanhar os avanços tecnológicos e de prestação de serviços, constata-se que o modelo de negócios adotado por elas é ineficiente e pouco competitivo. Isso talvez se reflita na falta de convergência entre os modelos de gestão das empresas de processamento de dados estaduais (Cunha, Marques e Meirelles, 2002). Além disso, observa-se que o modelo de gestão dessas empresas não segue a mesma lógica empresarial observada nas empresas privadas de prestação de serviços de TIC, cujo modelo de gestão está apoiado no controle rigoroso de custos, no conhecimento das suas margens de lucro, na capacidade de autoinvestimento e no conhecimento das necessidades de seus clientes.

Apesar disso, existem muitas iniciativas de sucesso nos três níveis de governo e em todos os poderes da República Federativa, conforme demonstrado por Chain e colaboradores (2004) e Ferrer e Santos (2004). São bem conhecidos os casos da Receita Federal, com a simplificação do processo de declaração de ajuste anual do IR, das compras governamentais pelo Pregão Eletrônico e das eleições gerais com o auxílio das urnas eletrônicas em nível nacional. Nos níveis estadual e municipal, a adoção de recursos tecnológicos e sistemas de informática pública vêm permitindo muitos avanços sociais: sistemas para o agendamento de consultas médicas em hospitais e postos de saúde; sistemas automatizados de matrículas escolares, que acabaram com as filas na porta das escolas públicas; lojas (praças) de atendimento integrado que, complementados pela entrega de serviços por meio dos portais governamentais na internet, dispensam a necessidade da presença física do cidadão nos órgãos públicos. 
Os primeiros estudos para a formulação de uma política federal de governo eletrônico foram elaborados pelo Grupo de Trabalho em Tecnologia da Informação (GTTI), uma comissão interministerial criada pelo decreto presidencial de 3 de abril de 2000, com a finalidade de examinar e propor políticas, diretrizes e normas relacionadas às novas formas eletrônicas de interação. O Programa de Governo Eletrônico resultante (Brasil, 2001) foi inicialmente implementado sob a coordenação política da Presidência da República, com apoio técnico e gerencial da Secretaria de Logística e Tecnologia da Informação (SLTI), do Ministério do Planejamento, Orçamento e Gestão. Essa atuação foi sustentada por um comitê integrado pelos secretários executivos (e cargos equivalentes) dos ministérios e órgãos da Presidência da República, denominado Comitê Executivo de Governo Eletrônico (Cege). O trabalho do GTTI, inicialmente, concentrou esforços em três linhas de ação do Programa Sociedade da Informação: universalização de serviços, governo ao alcance de todos e infraestrutura avançada (Comitê Executivo E-gov, 2002).

A proposta partiu da existência de um amplo conjunto de serviços na internet e de um portal único de serviços e informações ao cidadão, denominado Rede Governo. ${ }^{3}$ A proposta procurou priorizar a incorporação das novas tecnologias da informação aos processos administrativos do governo e à prestação de serviços ao cidadão. Inicialmente, foram implantados no portal Rede Governo, no final de 2001, cerca de 1.350 serviços e 11 mil tipos de informação disponíveis. No final de 2002, o número de serviços já havia crescido para cerca de 1.700, com aproximadamente 22 mil links de acesso direto a serviços e informações de outros websites governamentais.

Já por ocasião da implantação do programa, o governo federal reconhecia que a falta de uma política integrada e abrangente para promover a efetiva universalização do acesso às tecnologias da informação e aos serviços seria um sério empecilho para o desenvolvimento do projeto (Brasil, 2002a, 2002b). Como quase tudo na internet, a infraestrutura dos serviços informatizados do governo federal estava fundada na operação de uma malha descentralizada, o que poderia comprometer o programa de diversas formas, seja pela falta de um padrão comum de atendimento, seja pela falta de intercomunicação por uma intranet governamental, ou ainda pela ausência de procedimentos legais mais específicos.

Em vista desses problemas, o governo priorizou a formulação de uma política de tecnologia da informação e comunicação orientada para a constru-

\footnotetext{
${ }^{3}$ Esse portal pode ser acessado em: <www.governoeletronico.redegoverno.gov.br/>.
} 
ção gradativa de uma arquitetura de relacionamentos envolvendo o governo, os cidadãos, parceiros de negócios e fornecedores, contemplando a atuação do governo em três frentes fundamentais: interação com o cidadão; melhoria e modernização da gestão interna; e integração dos processos e serviços do governo com a cadeia produtiva de parceiros e fornecedores, articulando-as sob condução do Comitê Executivo de Governo Eletrônico (Brasil, 2001).

A partir de 2003, o Ministério do Planejamento, Orçamento e Gestão, por meio da Secretaria de Logística e Tecnologia da Informação (SLTI), exerce as atribuições de secretaria executiva do Programa de Governo Eletrônico, garantindo o apoio técnico-administrativo necessário ao funcionamento do Comitê Executivo de Governo Eletrônico. Em 29 de novembro de 2003, a Presidência da República publicou um decreto que instituiu oito comitês técnicos no Comitê Executivo do Governo Eletrônico: inclusão digital; gestão de sítios e serviços online; implementação do software livre; integração de sistemas; infraestrutura de redes; gestão do conhecimento e informação estratégica; governo para governo; e sistemas legados e licenças de software.

Segundo Pinto e Fernandes (2005), apesar do sucesso na institucionalização do Programa de Governo Eletrônico, ele vem perdendo a prioridade governamental deste a transição de governo ocorrida em 2003. Segundo os autores isso se deve a quatro fatores principais:

- mudança da liderança política - o papel exercido pelo chefe da Casa Civil, Pedro Parente, não foi desempenhado com a mesma desenvoltura pelos novos representantes no governo Lula;

v falta de coordenação intraburocrática - inexistem instâncias de coordenação do Programa de Governo Eletrônico dentro de cada ministério, o que dificulta a execução de ações integradas;

v dificuldade de articulação com a sociedade - as restrições legais do setor público ainda geram pouco estímulo ao estabelecimento de parcerias com a iniciativa privada, aprofundando a incerteza sobre o modelo de relacionamento entre empresas prestadoras de serviço de TIC e o governo;

$\checkmark$ falta de recursos - projetos de governo eletrônico possuem poucos recursos e são rotineiramente sujeitos a contingenciamento. Iniciativas de sucesso tendem a ser setoriais, normalmente desintegradas de uma solução estratégica de governo.

Complementarmente, o Tribunal de Contas da União apresentou extenso relatório sobre o Programa de Governo Eletrônico no período de gestão do 
governo Lula, com objetivo de "avaliar de que maneiras as ações do programa têm contribuído para a oferta dos serviços públicos eletrônicos diretamente ao cidadão" (TCU, 2006:239). O relatório coletou dados de 4.944 usuários entre outubro e novembro de 2005 e concentrou sua análise em duas das 13 ações do Plano Gerencial para Governo Eletrônico do Ministério do Planejamento: aprimoramento e normatização do portal de governo eletrônico e sites coligados; e sistema de atendimento ao cidadão por meio eletrônico.

O relatório do TCU reafirma a dificuldade de coordenação do programa e a falta de monitoramento das iniciativas de governo eletrônico da administração pública federal. Entre as principais recomendações estão:

、 criação de um portal único de governo eletrônico, cujas alterações de conteúdo, relativas aos serviços, estejam sob a responsabilidade de uma única entidade governamental, órgão ou setor;

v revisão do modelo institucional do Programa de Governo Eletrônico;

v participação efetiva do Cege na gestão do programa, através da criação de cronograma e indicadores de desempenho, além da elaboração e disseminação de documentos com dados atualizados do programa.

\section{Análise das entrevistas com atores-chave}

Para este artigo foram entrevistados atores-chave que participaram do processo de construção do Programa de Governo Eletrônico na gestão do presidente Fernando Henrique Cardoso (1999-02) e na gestão do presidente Luiz Inácio Lula da Silva (2003-06). ${ }^{4}$

A coleta de dados em entrevista mostrou-se rica em informações estratégicas, complementando a análise documental e trazendo elementos importantes para a validação do modelo de referência proposto, principalmente quanto às fases, atores e fatores influenciadores do processo. Além disso, as entrevistas trouxeram fatos não documentados e conceitos relevantes para a pesquisa. As entrevistas foram realizadas durante o segundo semestre de 2005 e primeiro semestre de 2006. O perfil de cada entrevistado é mostrado no quadro 3.

\footnotetext{
${ }^{4}$ Originalmente estavam previstas quatro entrevistas: duas com gestores do período FHC e duas com gestores do período Lula. Um dos convidados a participar das entrevistas, Rogério Santana, secretário de Logística e Tecnologia da Informação do Ministério do Planejamento do governo Lula acabou não participando por problemas de agenda.
} 
Quadro 3

Perfil dos entrevistados

\begin{tabular}{|llll|}
\hline Nome & Cargo & Gestão & $\begin{array}{l}\text { Data da } \\
\text { entrevista }\end{array}$ \\
\hline Pedro Parente & Secretário da Casa Civil & FHC & Nov. 2005 \\
Solon Pinto & Secretário do Comitê Executivo de Governo Eletrônico & FHC & Set. 2005 \\
Patrícia Pessi & Diretora do Departamento de Governo Eletrônico & Lula & Maio 2006 \\
\hline
\end{tabular}

Como resultado das entrevistas, foi apontada a existência de oito fatores influenciadores no processo de construção do Programa de Governo Eletrônico no Brasil, que não foram identificados na análise documental. Esses fatores permitem construir um panorama histórico do governo eletrônico no Brasil mais coerente.

\section{O "bug do milênio" foi um mecanismo estruturador do programa de e-gov no Brasil}

Apesar da Secretaria de Logística e Tecnologia da Informação (SLTI) já estar envolvida no planejamento de ações relacionadas à TI, os entrevistados ressaltaram a importância do "bug do milênio" para a estruturação das ações do Programa de Governo Eletrônico brasileiro. Por se tratar de uma iniciativa de âmbito nacional, as ações para enfrentamento do bug foram consideradas um projeto estratégico do governo, geridas diretamente pela Casa Civil e coordenadas operacionalmente pela SLTI. O principal papel da SLTI foi o mapeamento dos impactos e a articulação dos diversos atores de TI para operar os ajustes necessários nos sistemas de informação. Seu relacionamento não foi restrito aos órgãos do governo federal, ocorrendo também junto aos estados, aos municípios, à iniciativa privada e à comunidade internacional.

O ceticismo que existia quanto à capacidade de coordenação da SLTI de grandes projetos foi minimizado pelo sucesso obtido nas ações relativas ao "bug do milênio". Essa legitimação da SLTI, como articuladora competente, foi de grande importância para os trabalhos que viriam a ser realizados pelo Comitê Executivo de Governo Eletrônico (Cege) junto aos diversos ministérios. Nas palavras do secretário executivo da SLTI, Solon Pinto (2005):

Então isso (o sucesso do projeto do bug) mostrou o seguinte: a área de TI do governo (...) deu um bom exemplo de que ela pode coordenar ações. Que não 
precisa ser uma coisa de cada um cuida da sua parte! Ela mostrou que pode fazer ações de coordenação, que eram sempre ações questionadas por esse modelo, SLTI.

Além disso, o fato também trouxe ao âmbito político a importância da TI, já que em 1999 sistemas críticos, como a malha de arrecadação federal, estavam baseados em sistemas de informação. A TI deixava de ser operacional e o bug demonstrou que o assunto carecia de maior supervisão. Como resultado do projeto do bug, parte do parque tecnológico foi atualizado, o que colaborou com algumas ações estruturantes a serem executadas posteriormente pelo Cege.

\section{O apoio marcante de Pedro Parente}

Pedro Parente era o ministro do então Ministério do Orçamento e Gestão $(\mathrm{MOG})^{5}$ durante a iniciativa do "bug do milênio" pela SLTI. Em 1999, ele assumiu o cargo de ministro da Casa Civil e foi responsável pela manutenção da SLTI como coordenadora de ações, estruturando-a formalmente através do Cege em outubro de 2000.

Aí, ele (Pedro Parente) e o Marcos (Tavares, ministro do MOG na época) conversaram e disseram o seguinte: "vamos aproveitar essa mobilização, que foi um sucesso do ano 2000 e vamos criar uma forma de coordenação, vamos criar um programa coordenado de informatização do governo" (...) Aí, surgiu aquele decreto de outubro de 2000.

(Solon Pinto, 2005)

Após a constituição do Comitê Executivo de Governo Eletrônico (Cege), a vontade política do governo, expressa pela presença de Pedro Parente nas reuniões do comitê, é considerada um dos fatores mais decisivos para que os obstáculos de prioridade e recursos fossem superados. Nas palavras do próprio Pedro Parente (2005):

Eles - SLTI - não tinham a força política necessária para intervir no momento adequado caso os ministérios não estivessem tomando as providências

${ }^{5}$ O MOG foi depois transformado no Ministério de Orçamento, Planejamento e Gestão (MPOG). 
necessárias (...) Então montamos um comitê de governo eletrônico que era liderado pelo ministro da Casa Civil, por mim, e que tinha secretários executivos. A gente fazia reuniões mensais desse grupo e o Solón era o secretário executivo desse comitê. A gente acompanhava através desse comitê as iniciativas, acompanhava o inventário, era importante fazer o inventário dos serviços que eram proporcionados pelas entidades do setor público, e aí olhava o que era possível fazer via governo eletrônico, o que não era possível. Assim é que funcionou.

Apesar do apoio do ministro, a atenção do MPOG estava mais direcionada para as questões orçamentárias do que para as iniciativas do e-gov. Assim, a SLTI ganhou maior autonomia e não houve resistência à participação direta da Casa Civil no processo. Os entrevistados consideram que houve baixa resistência não somente do aparato estatal, mas da própria sociedade. Apesar de a sociedade apoiar as iniciativas, o apoio não foi forte. Segundo Pedro Parente (2005), o motivo disso era que a sociedade não conseguia vincular as ações do programa e-gov aos resultados que já vinham ocorrendo.

A sociedade gostava (do programa de e-gov). Mas é aquela coisa: como eles não conseguiam dimensionar qual seria o ganho porque não conheciam (...) então a sociedade não conseguia atribuir ao novo processo de coordenação a importância e os resultados pretendidos, porque os resultados já vinham acontecendo.

\section{Os efeitos da crise energética e suas consequências no programa de e-gov}

A crise energética brasileira, popularmente conhecida como "apagão", ocasionou uma mudança de prioridade da Casa Civil com relação ao programa de e-gov. Pedro Parente, que vinha supervisionando de forma bastante próxima os trabalhos do Cege, acabou por assumir em maio de 2001 a Câmara de Gestão da Crise. A perda de prioridade dentro do governo, refletida pela ausência da Casa Civil nas reuniões do Cege, resultou em uma diminuição do ritmo das ações.

Com o apagão, eu fui obrigado a assumir a coordenação da Câmara de Gestão da Crise de Energia e aquilo me tomou muito tempo. Óbvio que aquilo era um elemento de força maior, eu tinha que tocar aquilo, o presidente me encarregou daquilo. E eu, a partir dali, não tive condição de dar ao processo a supervisão 
que vinha dando. De fato aconteceu, embora no meu modo de ver, não tenha havido retrocesso, só não prosseguiu com a mesma velocidade.

(Pedro Parente, 2005)

\section{As influências do processo eleitoral}

Com o governo FHC surpreendido com a crise energética e o fortalecimento do então candidato Lula, a prioridade governamental vinculou-se à entrega de um governo com estabilidade macroeconômica. Com isso, a possibilidade de perda de continuidade devido ao processo eleitoral, em que o candidato do governo tinha chances cada vez mais reduzidas, provocou uma desmotivação das equipes para trabalhos de longo prazo: "começa com o apagão em maio de 2001 e liga isso com o processo de eleição, em que o candidato do governo vai perdendo visibilidade porque se vê que ele não ganha a eleição, tudo isso tirou completamente a condição de fazer coisas mais estruturantes" (Pedro Parente, 2005).

\section{Os efeitos da transição do governo FHC para o governo Lula}

Durante o ano de 2003 houve uma grande descontinuidade dos trabalhos relacionados ao Cege. Somente a partir de julho de 2004, com a publicação do decreto de criação do Departamento de Governo Eletrônico na SLTI, os trabalhos foram retomados com maior efetividade.

Em 2003 teve uma descontinuidade bem significativa, por quê? Porque eu creio que durante uns 10 meses, nos primeiros quatro meses continuou o antigo diretor de programa (...) E depois de um tempo... a gente ficou uns três meses no máximo e eu cheguei em novembro no final de 2003, então foi um ano que assim... do ponto de vista... teve realmente uma queda, uma descontinuidade nas ações que aconteciam relacionadas a esse tema de serviços por meios eletrônicos.

(Patrícia Pessi, 2006)

Apesar de um programa de transição ter mantido alguns funcionárioschave para preservar o conhecimento e a dinâmica do processo, aparentemente esse período não foi suficiente para não haver perda de ritmo dos trabalhos. 
Quando cheguei na secretaria (novembro de 2003) para essa área, também tinha uma descontinuidade de pessoas né... e como era uma direção de programas, a maioria dos funcionários ou eram de terceiros ou eram funcionários que não permaneceram, então não havia mais ninguém da gestão anterior.

(Patrícia Pessi, 2006)

\section{Pesquisa como orientadora de ações do governo Lula}

Como suporte às ações estratégicas de governo eletrônico foi realizada em 2004, em parceria com a iniciativa privada, uma pesquisa sobre o uso de governo eletrônico envolvendo mais de 600 pessoas, 150 empresas e 57 instituições públicas em 10 capitais. Essa pesquisa, aprimorada com base em uma pesquisa realizada pelo governo anterior, mostrou a falta de alinhamento entre oferta e demanda de serviços eletrônicos. As ações estratégicas tomadas com base na pesquisa orientaram o desenvolvimento de novos serviços, que foram incorporados a uma visão baseada em eventos da vida.

\section{Avaliação da qualidade dos serviços eletrônicos}

Em dezembro de 2004 foi iniciado um estudo sobre a avaliação dos serviços disponibilizados de governo eletrônico. O estudo abrangeu a identificação de indicadores e métricas de governo eletrônico. Atualmente encontra-se em implantação um piloto dessa metodologia em sete serviços federais, sete estaduais e sete municipais.

\section{A dificuldade de articulação e priorização}

A capacidade de superar obstáculos e priorizar atividades é identificada como um problema tanto no final da gestão FHC quanto na gestão Lula. Um dos motivos destacados é a falta de poder de articulação da SLTI junto aos demais ministérios.

Acho que o principal desafio daqui pra frente é de alguma maneira institucionalizar uma instância, um fórum (...) que tem poder administrativo e político pra fazer a gestão desse processo de implantação de serviços por meios eletrônicos... que não é um departamento dentro de uma secretaria vinculada a um 
ministério... realmente o que nós podemos fazer é propor essa estrutura... mas sermos essa estrutura pela forma como se estrutura o poder, a gestão, e tudo mais, um governo enorme como é o governo federal... é muito difícil.

(Patrícia Pessi, 2006)

Essa falta de legitimidade dentro do próprio governo, que não reconhece a SLTI como um órgão centralizador das ações de governo eletrônico, resulta na baixa coordenação das ações ministeriais. Os instrumentos criados para interagir com os ministérios estão mais relacionados a motivações pessoais do que a ações institucionais. Segundo Patrícia Pessi (2006) "o último movimento que nós fizemos em relação aos ministérios... são movimentos assim de sensibilização na verdade, né... olha está aqui a pesquisa... mostra que as prioridades são tais, tais, tais... então acreditamos que se vocês construírem a agenda de vocês... têm a possibilidade de ser mais felizes".

Uma consolidação dos principais marcos observados na análise dos documentos e entrevistas é apresentada na figura 2 .

Figura 2

Perspectiva da história do governo eletrônico no Brasil

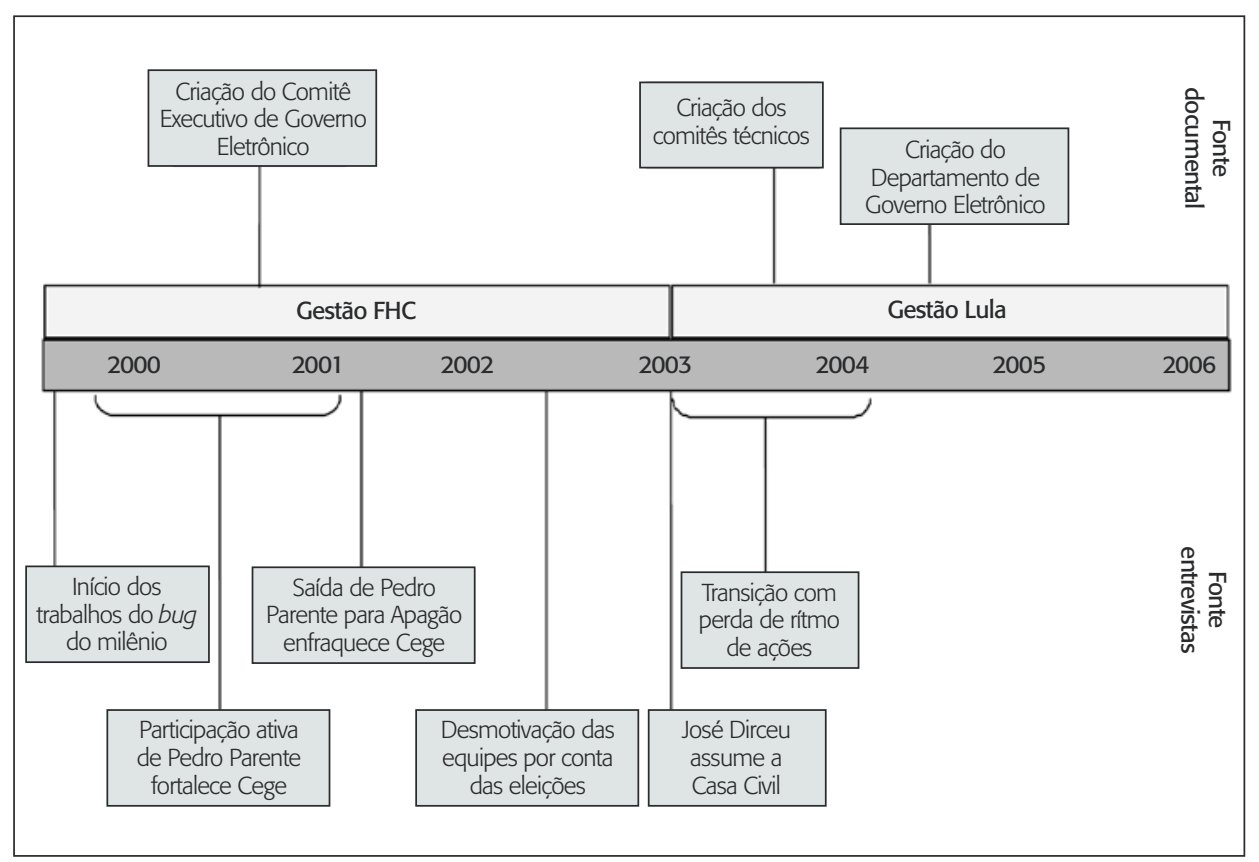




\section{Considerações finais}

Assim como as iniciativas na área de governo, os estudos sobre governo eletrônico vêm se desenvolvendo com grande velocidade. A compreensão das principais variáveis que determinam o sucesso ou fracasso das iniciativas é importante para estruturar o grande volume de informação existente e possibilitar a análise e estudo da história do governo eletrônico no Brasil.

Neste artigo foi apresentada uma nova abordagem para o estudo desse tema, principalmente no contexto de evolução de programas de governo. Foram apresentados os principais marcos teóricos do Programa de Governo Eletrônico brasileiro, assim como um modelo de referência para auxiliar a análise das informações coletadas. A abordagem proposta contempla uma visão sobre os processos (etapas), sobre os agentes atuantes (atores) e sobre aspectos influenciadores, e também o inter-relacionamento entre eles.

Foi possível identificar, por meio de um levantamento, que o Programa de Governo Eletrônico brasileiro tornou-se viável por influência de uma iniciativa anterior, até então não claramente mencionada na literatura, o "bug do milênio". Toda a mobilização feita para saneamento do "bug" acabou por promover as estruturas necessárias para que a SLTI assumisse o papel de coordenadora junto aos demais atores.

A contribuição deste artigo está na apresentação de uma proposta para o estudo da história do governo eletrônico no Brasil, estruturada em um quadro de referência. O modelo apresentado não tem a pretensão de exprimir a realidade em toda a sua complexidade, mas capturar os aspectos principais que devem ser analisados e compreendidos quando da evolução de um programa de e-gov. Como afirmado por Frey (2000:229):

O modelo de policy-cycle é um tipo puro idealizador do processo político, na prática dificilmente este se dá de acordo com o modelo. Porém, o fato de os processos políticos reais não corresponderem ao modelo teórico não indica necessariamente que o modelo seja inadequado para a explicação destes processos, mas sublinha o seu caráter enquanto instrumento de análise.

\section{Referências bibliográficas}

ABRANSON, M.; MEANS, G. E. E-government 2001 - IBM endowment for the business of government. Rowman \& Littlefield Publishers, 2001. 
AGUNE, R.; CARLOS, J. Governo eletrônico e novos processos de trabalho. In: LEVY, E.; DRAGO, P. (Orgs.). Gestão pública no Brasil contemporâneo. São Paulo: Fundap, 2005.

ALADWANI, A. IT planning effectiveness in a developing country. Journal of Global Information Management, v. 4, p. 51, 2001.

BAHIENSE, G.; NOGUEIRA, R. Uso estratégico de tecnologia da informação em secretarias de Fazenda no Brasil. In: ENCONTRO ANUAL DA ASSOCIAÇÃO NACIONAL DE PÓS-GRADUAÇÃO EM ADMINISTRAÇÃO, 26., 2002, Salvador. Anais eletrônicos... Salvador: Enanpad, 2002.

BARBOSA, A.; FARIA, F; PINTO, S. Organizando os ativos tecnológicos do governo: modelo de referência para a implantação de programas de governo eletrônico centrado no cidadão. In: CLADEA, 2005, Santiago. Anais... Chile: Cladea, 2005.

BARBOSA FILHO, D. F. Governo eletrônico - uma nova forma de gestão da administração pública para o século XXI. Rio de Janeiro: Coppe/UFRJ, 2000. v. 3.

BEHN, R. D. O novo paradigma da gestão pública e a busca da accountability democrática. Revista do Serviço Público, Brasília, DF, ano 49, n. 4, out./dez. 1998.

BRASIL. Proposta de política de governo eletrônico para o Poder Executivo federal. Grupo de trabalho "novas formas eletrônicas de interação". Brasília: Ministério do Planejamento, Orçamento e Gestão, 2000.

. Presidência da República. Comitê Executivo do Governo Eletrônico. A política de governo eletrônico no Brasil. Brasília, DF, 2001. 8 p. Disponível em: <www.governoeletronico.gov.br/governoeletronico/index.html>. Acesso em: 14 maio 2006.

. Presidência da República. Comitê Executivo do Governo Eletrônico. Dois anos de governo eletrônico: balanço de realizações e desafios futuros. Brasília, DF, 2002a. Disponível em: <www.governoeletronico.gov.br/arquivos/Balanco_2_Anos_ Egov.pdf > . Acesso em: 26 abr. 2003.

. Presidência da República. Comitê Executivo do Governo Eletrônico. Levantamento das ações de governo eletrônico. Brasília, DF, 2002b. Disponível em: <www. governoeletronico.gov.br/arquivos/Anexo_Balanco_Inventario.pdf $>$. Acesso em: 26 abr. 2003.

BRESSER-PEREIRA, L. C. Reforma da nova gestão pública: agora na agenda da América Latina, no entanto... Revista do Serviço Público, ano 53, n. 1, jan./mar. 2002.

BRETSCHNEIDER, S. Management information systems in the public and private organizations: empirical test. Public Administration Review, ano 5, n. 50, p. 536545, Sept./Oct. 1990. 
CHAIN, A. et al. E-gov.br: a próxima revolução brasileira. São Paulo: Prentice Hall, 2004.

CHECCI, R. M.; HSIEH, J.; STRAUB, D. Public IT policies in less development countries: a critical assessment of the literature and a reference framework. Journal of Global Information Technology Management, v. 6. p. 45, 2003.

COMITÊ EXECUTIVO E-GOV. Dois anos de governo eletrônico: balanço de realizações e desafios futuros. Brasília: Casa Civil da Presidência da República, Ministério do Planejamento, Orçamento e Gestão, Secretaria Executiva, 2002.

CUNHA, M. A.; MARQUES, E.; MEIRELLES, F. Tecnologia de informação no setor público: estudo da percepção dos gestores do Executivo estadual. In: ENCONTRO ANUAL DA ASSOCIAÇÃO NACIONAL DE PÓS-GRADUAÇÃO EM ADMINISTRAÇÃO, 2002, Salvador. Anais eletrônicos... Salvador: Enanpad, 2002.

DINIZ, E. H. Uso do comércio eletrônico em órgãos do governo. Relatório 18/2000 NPP. Eaesp/FGV, maio 2000. 100 p.

DINIZ, V. A história do uso da tecnologia da informação na gestão pública brasileira através do CONIP — Congresso de Informática Pública. In: CONGRESO INTERNACIONAL DEL CLAD SOBRE LA REFORMA DEL ESTADO Y DE LA ADMINISTRACIÓN PÚBLICA, 10., 2005, Santiago. Anales... Chile, 2005.

FERLIE, E. et al. The new public management in action. Oxford: Oxford University Press, 1996.

FERRER F; SANTOS, P. (Orgs.). E-government: governo eletrônico no Brasil. São Paulo: Saraiva, 2004.

FREY, K. Políticas públicas: um debate conceitual e reflexões referentes à prática da análise de políticas públicas no Brasil. Planejamento e Políticas Públicas, Brasília: Ipea, v. 21, p. 211-259, 2000.

GIL-GARCIA, J., PARDO, T. E-government success factors: mapping practical tools to theoretical foundations. Government Information Quarterly, v. 22, p. 187-216, 2005.

GRANT, G.; CHAU, D. Developing a generic framework for e-government. Journal of Global Information Management, v. 13, n. 1, Jan./Mar. 2005.

GUPTA, M. P.; JANA, D. E-government evaluation: a framework and case study. Government Information Quarterly, v. 20, p. 365-387, 2003.

LENK, K.; TRAUNMÜLLER, R. Electronic government: where are we heading? In: ELECTRONIC GOVERNMENT, FIRST INTERNATIONAL CONFERENCE, 2002, Aixen-Provence, France. Proceedings... 2002. p. 1-9. 
MEDEIROS, P. H. Governo eletrônico no Brasil: aspectos institucionais e reflexos na governança. Dissertação (Mestrado em Administração) — Universidade de Brasília (UnB), Brasília, 2004.

OSBORNE, D. Banishing bureaucracy: the five strategies for reinventing government. New York: Plume, 1997.

PETERS, B. G. The policy capacity of government. Ottawa: Canadian Centre for Management Development, 1996.

PINTO S.; FERNANDES, C. Institucionalização do governo eletrônico no Brasil. In: CONGRESO INTERNACIONAL DEL CLAD SOBRE LA REFORMA DEL ESTADO Y DE LA ADMINISTRACIÓN PÚBLICA. 10., 2005, Santiago. Anales... Chile, 2005.

POLLIT, C.; BOUCKAERT, G. Public management reform: a comparative analysis. New York: Oxford University Press, 2000.

PRADO, O. Governo eletrônico e transparência: a publicização das contas públicas das capitais brasileiras. 2004. 180 p. Dissertação (Mestrado em Administração de Empresas) - Escola de Administração de Empresas de São Paulo da Fundação Getulio Vargas, São Paulo, 2004.

REINHARD, N.; DIAS, I. Categorization of e-gov initiatives: a comparison of three perspectives. In: CONGRESO INTERNACIONAL DEL CLAD SOBRE LA REFORMA DEL ESTADO Y DE LA ADMINISTRACIÓN PÚBLICA, 10., 2005, Santiago. Anales... Chile, 2005.

RONAGHAN, S. Benchmarking e-government: a global perspective. Assessing the progress of the UN member states. United Nations Division for Public Economics and Public Administration \& American Society for Public Administration, May, 2002.

TAN, C.; PAN SHAN, L. Managing stackeholder interests in e-government implementation: lessons learned from a Singapore e-government project. Journal of Global Information Management, v. 13 p. 31, 2005.

TCU (Tribunal de Contas da União). Ata n. 32, de 9 de agosto de 2006. Brasília, DF: Tribunal de Contas da União, Secretaria Geral das Sessões, 2006.

TORRES, G. G. Esboço de um modelo de gestão governamental da informática, informação e comunicação. Reunión sobre Tendencias y Desafios de la Gestión de la Información y TI. ONU. Chile, 1997. 